\title{
Whatever It Takes! Developing Professional Learning Communities in Primary School Mathematics Education
}

\author{
Marilyn Chaseling1, William Edgar Boyd ${ }^{2}$, Karen Robson ${ }^{3}$, Luke Brown ${ }^{3,4}$ \\ ${ }^{1}$ Centre for Children and Young People, Southern Cross University, East Lismore, Australia \\ ${ }^{2}$ School of Environment, Science \& Engineering, Southern Cross University, East Lismore, Australia \\ ${ }^{3}$ St Peter's Primary School, Port Macquarie, Australia \\ ${ }^{4}$ Our Lady Help of Christians School, Earlville, Australia \\ Email: marilyn.chaseling@scu.edu.au
}

Received 3 January 2014; revised 28 January 2014; accepted 15 February 2014

Copyright (C) 2014 by authors and Scientific Research Publishing Inc.

This work is licensed under the Creative Commons Attribution International License (CC BY). http://creativecommons.org/licenses/by/4.0/

(c) (i) Open Access

\begin{abstract}
In recognising the need to develop skills in numeracy teaching in a regional primary school, this paper examines a case study of one school response. The Principal of the school instigated the development of professional learning communities, to assist all the teachers, who are not numeracy specialists, to develop appropriate classroom skills. This study describes the early stages of this development, using the beginning of a planned action research approach to reflect on the processes and success of the development. Through staff feedback and participant observation, a general satisfaction with the process and its outcomes is recorded. A benchmarking exercise against a published case study in an American middle school setting identifies where that success originates from-the adoption and articulation of key concepts and principles, the role of deliberative leadership, the creation of a safe working environment, and a number of practices considered crucial to the success of professional learning communities. However, the benchmarking exercise also identifies weaknesses in the case study, which helps explain some misgivings that some staff express about the process, in particular a default assumption about staff recruitment, and a weakness of managing time to account for existing staff time demands.
\end{abstract}

\section{Keywords}

Numeracy Teaching, Professional Development Communities, Teacher Professional Development 


\section{Introduction}

In the last decade, there has been an increasing level of concern in Australia about decreasing numeracy levels for Australian students (HCWG, 2008). The latest Organisation for Economic and Co-operative Development figures rank the mathematical achievements of Australian 15 year olds as 16th in the world. This represents a fall from second in the previous report (PISA 2009 Results in Thomson et al., 2011).

One response has been the Australian Government's Smarter Schools National Partnership for Improving Teacher Quality program, which provided funds to States and Territories over a five-year period aimed at improving the quality of Australian teachers (DEEWR, 2011). Funding received from this source by the Catholic Education Office in Lismore (regional New South Wales, Australia) supported a number of initiatives, including the In-house Inquiry project, a partnership with the Centre for Children and Young People at Southern Cross University (Thornton et al., 2011). The In-house Inquiry project provided a number of local schools with resources to engage in a project aimed at improving aspects of the school's performance. This paper reports on the outcomes of the first stage of research arising from this project, in which a professional learning community (Koellner et al., 2011) was formed in a school to improve numeracy outcomes for students. The study focuses on the in-school processes at this initial stage of project implementation, rather than analysing student performance indicators, to assess the strength and form of staff engagement with the project; it is responding to Lloyd's (2013: p. 161) observations that "much of the research in our field aims to document, understand, and measure the impact of opportunities for teachers to learn through diverse experiences ranging from coursework to practicebased professional learning communities”. As such, this paper contributes to the identified need for further research into mathematics educator education (Goos, 2009). Given the conceptual influence of Koellner et al. (2011) on the program described here, our analysis will be framed by benchmarks derived from Koellner et al.'s work. Research regarding student performance will be relevant once the process has been in place for longer.

When Michael Fullan, the world authority on educational change, wrote on the topic of educational change in the 1980s, he argued that educational change was difficult to accomplish. Fullan maintained that a commitment to change by reformers did not necessarily mean that a particular change would be implemented (Fullan, 1982). Further, even when policy-makers legislate that schools achieve certain goals, there was no guarantee that these goals will be achieved. He argued that deep-rooted factors work against change, and that the most beneficial approach is to understand the change process and then to work to influence the factors that are changeable and minimise those which are not.

Writing a quarter of a century later, Fullan later reflected that educational reform had been more complex than expected. For sustainable change to occur, a tri-level whole-system approach is required involving local schools and the community, the district, and the state or nation (Fullan, 2007). For Fullan, these three elements must be intimately interconnected to achieve large-scale reform. Notwithstanding this conception of the conditions for change, Fullan declared that educational change is dependent on teachers-what they do and what they think: "It's as simple and as complex as that", he claimed (Fullan, 2007: p. 129). It is the cultures of classrooms, schools, districts, universities and other related contexts that must change. The changes need to enable teachers to work together naturally, both physically and attitudinally, to plan, observe each other's practice, and to seek and test and revise their teaching strategies on a continuing basis (Boyd et al., 2008; Boyd \& Newton, 2011; Den Exter et al., 2012). Fullan reports research that students did much better when they had three good teachers in three successive years (Fullan, 2007). Further, when schools were led by principals who encouraged strong professional communities, there was a much greater likelihood that students would experience a succession of three good teachers, whether that be three teachers over the years or on the same day. The creation of professional learning communities provides one approach to addressing this need (DuFour et al., 1998; Schmoker, 2005; Stiggins, 2005; Thornton et al., 2011). It requires teachers to work together to facilitate change in schools. A true professional learning community only comes about when collegial staff work collaboratively to address student learning. Commonly, a school community has a "whatever it takes" attitude to student learning: the whole community will do whatever it takes to ensure that all children will achieve at high levels. Professional literature is clear on the benefits for students and their learning when a school is able to become a learning community. DuFour and Eaker (1998) described six characteristics of a learning community; such a community needed to: have a shared vision, mission, values, goals; work as collaborative teams; engage in collective inquiry; action orientation/experimentation; have a commitment to continuous improvement; and be results orientated.

The context of this study is the development of a professional learning community in a school to support 
teaching staff in addressing numeracy education needs. According to the HCWG's (2008) National Numeracy Review, there are questions about the adequacy of the Australian education system to serve the needs of students in numeracy. There are five most frequently expressed concerns related to Australian students (HCWG, 2008: p. 2): students are not learning what are regarded as the "basics", with the result that they are not adequately equipped for future study or employment; relative to other countries, Australian students do not perform well; at the lower end of international tests, Australia has a long "tail" of poor achievement; particular socio-economic, geographical, cultural and racial/ethnic factors can be an indication of low achievement; and at both the senior secondary and tertiary levels, enrolments in mathematics are declining, which, it is claimed, will have grave consequence for the future places. The report continues to state that, in Australia, numeracy interventions are likely to focus on students who may not meet National Benchmarks. However, at Years 3 and 5, the National Benchmarks measure minimum standards instead of appropriate proficiency levels. This suggests that these lower standards are all that are needed for some students. On the contrary, Australian students and their families should expect high numeracy quality through education, rather than minimum outcomes (p. 13). The question, therefore, arises, as to the effectiveness of professional learning communities as a means to addressing this need and expectation. We examine this question through a case study approach (Yin, 2009).

\section{The School Context}

The study was conducted in a medium sized Catholic primary school in a regional city on the north coast of New South Wales, Australia. With an enrolment of approximately 400 students, the school draws its population from its surrounding and newly established beachside suburbs. The ICSEA (Index of Community SocioEducational Advantage) score for the school is 1056 indicating that the parent population has relatively high levels of education and income. The school has 14 classes; two classes for each year level from Kindergarten (pre-Year 1) to Year 6 (abbreviated to K-6). Each class is of mixed-ability groupings. The teaching in the school is undertaken by a combination of full-time and part-time teachers. A total of 17 teachers are employed full-time, while four teachers work part-time. In addition, a Reading Recovery teacher works in the school for four days week. As part of its library program, weekly information technology lessons are delivered to all students from K-6 by part-time teachers. The school's focus on curriculum, special education, sport and ICT (information and communication technology) sees one teacher responsible for coordinating each of these areas. This school is led by a non-teaching principal responsible to the local Parish priest and the Catholic Education Office in the regional centre of Lismore. He is supported in managing the school and its curriculum by a Deputy Principal who, in 2010, taught one class for two days per week.

In 2009, as part of a school review process, the school developed a five-year strategic plan. Various areas were identified as needing improvement, and goals were identified. Two Teaching and Learning goals, for example, related to numeracy: investigate further professional development opportunities in the teaching of numeracy; and investigate and establish a whole school approach to the teaching of numeracy. The focus for staff in 2010 was to redevelop the school's behaviour management plan and its anti-bullying policy. For 2011, numeracy was chosen as the focus area, with the aim of improving students' numeracy achievement levels. Discussion with, and amongst, staff indicated that they generally felt quite confident in teaching literacy, and had had many opportunities to participate in literacy professional development. However, they had less confidence in teaching numeracy, as this area had a history of lower priority in time and resources. This lower confidence is reflected in the school's NAPLAN results (NAPLAN is a national annual school children's testing program, focussing on reading, writing, language conventions and numeracy: ACARA, 2012). While both literacy and numeracy NAPLAN results for the school are above the national average, numeracy results are consistently outperformed by literacy.

\section{Background to the Project}

The project resulted from the vision of the school's Principal. In October 2010, the regional Catholic Education Office organised a professional development tour for its regional Principals to observe what is considered to be exemplary 21st century teaching and learning thinking in Melbourne schools. This provided an opportunity to observe many innovations in school practice, such as team literacy and numeracy meetings, innovative coordinator structures (including stage based coordinators), pre- and post-testing structures (including online resources), 
cooperative open-plan classrooms, integrated devices across all key learning areas, cooperative planning teams, student-led learning contracts, explicit teaching goals, visual representations of student performance data, student portfolios, three-way learning conferences, exclusive use of teachers as opposed to the incorporation of teaching assistants, as well as a highly structured and data driven approach to learning. The practice the Principal saw as having the greatest potential to transform aspects of his school was groups of teachers working together as professional learning communities. Staff professional development took place through these professional learning communities, which comprised Professional Learning Teams and a Learning Partner, who guided each team. On his return to the region, the Principal discussed his vision for the school with the Deputy Principal, and provided her the opportunity to explore the idea within their school.

In January 2011, the first author attended the Australian Council for Educational Leaders (ACEL) Summer School-a three-day intensive program that provided deep-dive learning sessions for educational leaders wishing to focus on new information and research, a deeper understanding of practical strategies and the development of a fresh set of skills to move learning forward and shift organisations from good to great (ACEL, 2011). This experience was important in providing input to perceptions and expectations for the development of the professional learning team program. The Summer School focused on: exploring what it means to create innovative learning environments for "this century" learners; examining the concepts of innovative and inquiry approaches to create engaging learning for young people; language that is congruent with influencing leadership and our current world of possibility and inquiry; learning the skills necessary to understand, engage in and facilitate different kinds of professional conversations and "learning talk" that transforms learning and fosters innovation; investigating the importance of being networked, of being adaptive and having a systems approach; and considering how "student voice" can transform learning environments. The Summer School also presented data that demonstrated that one of the greatest impacts on student learning was the connectivity of staff in working together to achieve a common goal. Seven core ideas for improved professional practice were discussed: engagement and metacognition; social nature of learning-cooperative learning; motivation and emotion; clear expectations and formative feedback; individual differences_-prior knowledge; hard work and challenge-and coherence; and horizontal connections.

Jointly enthused by the potential of professional learning communities, the Principal and Deputy Principal planned the 2011 Term One weekly staff meetings to develop a collaborative culture and shared vision within the staff. During the term, these meetings produced a series of documents. First, in 2010, as part of the school's Behaviour Management Plan, staff and students had worked together to create a Students' Rights and Responsibilities Charter; it was considered then that a similar document should be developed for staff by staff. During the Term One staff meetings, the Principal and Deputy Principal guided the staff through the development of a Staff Rights and Responsibilities Charter. An outcome of this process was a belief that staff needed to develop a way of interacting with each other when having professional conversations. The resulting document, a Covenant, reflects staff commitment to working together to promote a Catholic, ethical, just and responsible work environment for all members of the school community, and outlined agreed behavioural expectations for staff when they were conducting, or participating in, professional conversations. The Covenant is used to assist in developing working relationships and enhancing effective student learning, and from it a rose an Agreed Practices Charter. Finally, in recognising that staff may falter in fulfilling their commitment within the Covenant, each individual produced a protocol on (i) how they would like to be approached if they breached the Covenant; and (ii) how they would respond when they were spoken to in the context of (i). While there was no compulsion for staff to sign their Covenant, each chose to, likening this process to the one they used with their students - that is a working contract.

At a subsequent Term 1 staff meeting, staff decided that numeracy would be the Key Learning Area to work on for 2011, and that professional learning communities was the preferred process for the remainder of 2011 to further numeracy. The practicalities of the process were as follow.

- Teachers of each grade would meet every second week in their release-from-face-to-face time to focus on numeracy. Each year group would be known as a Professional Learning Team.

- A Learning Partner, the Deputy Principal, would participate in each meeting to help promote numeracy.

- The Monday staff meetings would include a professional development focus on numeracy, and the focus of the bi-weekly team meetings should aim to align with this. Key numeracy concepts to be considered in staff meetings would include: 
o Data-proven components of effective numeracy block;

o Assessing the current reality of mathematical skill achievement per grade and effective planning to meet needs;

o Implementation of school-wide numeracy block and agreed components;

o SMART goal setting per grade for the second semester of 2011.

\section{Evaluating the Program: The Project's Aim, Research Question and Method}

The study began at the beginning of Term II at the point when Professional Learning Teams had just been formed. The aim was to provide an initial exploration of how a Learning Partner worked in a school with Professional Learning Teams, and how this interaction could be developed to enhance the engagement of the learning teams and the professional learning community in a school (cf. Hunter, 2010). To address these two research questions, the study addressed questions regarding how the Learning Partner, Professional Learning Teams and individual teachers engaged with each other, and what teachers saw to be their own learning improvements and the changed required for their students' outcomes to improve. The primary interest, therefore, is not so much in the day-to-day teaching decisions and actions that emerged from this process, but in establishing a provisional sense of the overall processes in developing further professional engagement of teachers with teaching.

Since there was no prior research on this program, and since the primary focus of the engagement between the researchers and the school was on the implementation of the program, an action research approach was an appropriate methodology for the overall project. This provided a frame for the necessarily provisional and continuous process of developing professional skills within the workplace (Johnson \& Christensen, 2012). In an educational context, Creswell (2012) lists the key characteristics of action research as: a focus on practical issues; a teacher-researcher examining his/her own practice; collaboration with others; a dynamic process involving a "spiral" of activities; a plan of action; the sharing of research locally with others who can promote change in their classrooms. Importantly, this approach allows the responsive adoption of diverse data collection methods (cf. Yin, 2009). Decisions of specific actions to tried out and evaluated on a day-to-day basis in the classroom were made at the regular fortnightly Team meetings, allowing a regular monitoring, feedback and review process to be put in place as part of the work cycle. This allowed for responsiveness amongst the Team members. During this study data was collected through observations of Professional Learning Teams, participant interviews, and an anonymous survey.

In Week 1, Term 2, an initial In-house Inquiry planning meeting was held between participants from the Catholic Education Office, the participating school, and Southern Cross University. This provided the first opportunity for the Deputy Principal and her university partner to meet and discuss the school's Term 2 professional learning community initiative and the opportunities this provided for research to continually improve the process. At this meeting the project's aims and research questions, as included above, were determined. Dual decisions were also made to focus the study on the Learning Partner - the Deputy Principal herself-and to solicit only anonymous teacher feedback in an effort to elicit frank opinions from participating teachers.

Prior to the commencement of the project, at the weekly Monday staff meeting in Week 2, the Principal and Deputy Principal established staff's understanding of the Professional Learning Teams, the role of each participant and how teams could best function to improve numeracy outcomes for students. Each Year level's Professional Learning Team meeting was set as one hour of face-to-face-release time in every even term week, beginning in Week 2. Staff were also advised that, as this was a research project, data would be collected throughout, and resultant new actions trialled on a continuing basis, with a view to continual improvement of the process.

On the Thursday of Week 4 the first opportunity arose for two forms of data collection-both undertaken by someone external to the school. The first involved the university partner, who visited the school to conduct unstructured observations of three Professional Learning Teams working with their Learning Partner. The purpose of the observations was to observe what was taking place with the teams in their real-world setting (Johnson \& Christensen, 2012: p. 206).

The second data collection was undertaken by a Catholic Education Office consultant, who visited the school specifically to interview the teachers. The consultant conducted confidential interviews seeking each teachers' views on: the purpose of Professional Learning Teams; how the Learning Partner engages the learning team to improve student performance; the Learning Teams’ views on the Learning Partner's and teachers' roles; how teachers learn best to develop their practice in teaching numeracy; and needs for their students' numeracy outcomes 
to improve.

The Learning Partner analysed the data from the Week 4 interviews and provided feedback to the school, feedback that resulted in the inclusion of a session on numeracy in the weekly staff meetings. From that point on, staff meetings considered best practice in numeracy and what research had shown in relation to this. Text Box 1 contains details of the content covered in the staff meetings. From this point on, each week's Learning Team meetings were run to discuss, implement and reflect on staff meeting content. In Term 3 Week 2 , after 12 weeks of working in their Learning Teams (which translates to six one-hour team meetings), teachers were invited to complete a short 6-question anonymous survey on their experience of Learning Teams.

Following these discussions, a structure (Table 1) was agreed to and each staff member signed the document agreeing to implement these components into their Mathematics Programme. Support staff indicated that they would like to ensure the following components and the mathematics framework are achieved.

\section{Text Box 1. Professional learning team meeting numeracy discussions content.}

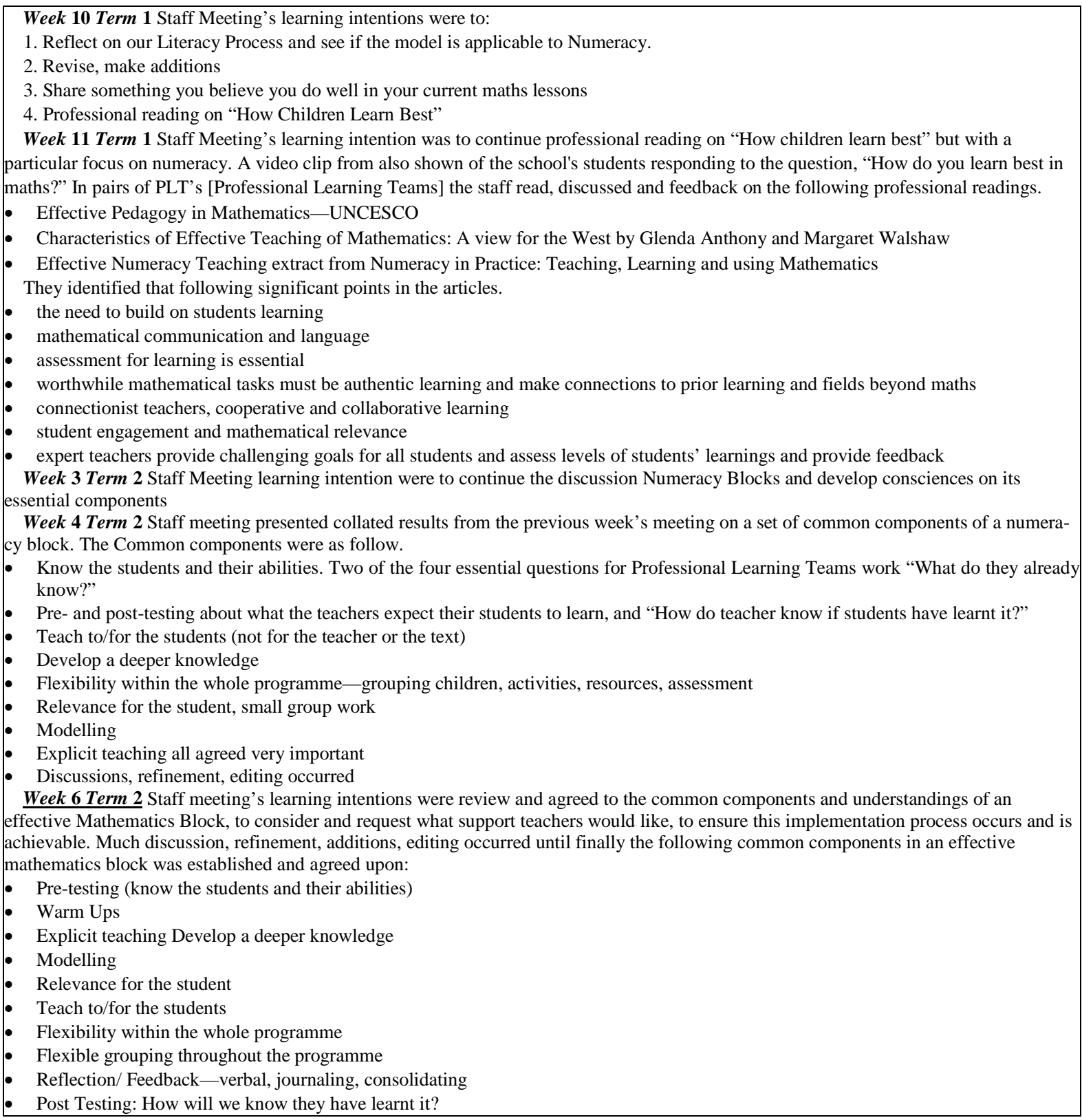


Table 1. Agreed-for delivery of the mathematics program as agreed through discussions by the teaching team.

\begin{tabular}{|c|c|}
\hline Stage & Suggested Support \\
\hline Early Stage 1/Stage 1 & $\begin{array}{l}\text { - } \quad \text { Extra teacher aides or teachers in the classroom during Maths Time. } \\
\text { - } \quad \text { Bore planning time and time to develop our own resources. } \\
\text { - } \quad \text { Reliable computers with relevant Maths Games. Beebots (IT resource) }\end{array}$ \\
\hline Stage 2 & $\begin{array}{l}\text { - } \quad \text { Collegial sharing time. Time for stage meetings. } \\
\text { - } \quad \text { Visiting other schools to look at technology use in numeracy. } \\
\text { - } \quad \text { Core resources_-knowing what is in other rooms to borrow. }\end{array}$ \\
\hline Stage 3 & $\begin{array}{l}\text { - Open-ended tasks and knowledge on how to rubric them. } \\
\text { - How to give effective feedback for learning. } \\
\text { - Ways to assist children who don't learn. }\end{array}$ \\
\hline
\end{tabular}

\section{Results}

\subsection{Feedback from the Observation Session}

The university partner made the following observations after sitting in on the sessions in Week 4. All Learning Team meetings took place in a room set up especially for the Professional Learning Team meetings. This light, airy room contained new furniture, including a meeting table and chairs, bookshelves for resources, and a computer with Internet. The walls were decorated with the charters developed by staff in Term I. Photographs of children engaged in various learning activities were strategically placed on the wall. The Learning Partner explained later that these were all photographs of staff children who attended the school. The wall also contained motivational posters. One read, for example, "Groups of teachers working together to ensure the best possible education for their students".

Three different one-hour Learning Team meetings were observed. There were three participants in each meeting - two teachers from the same year who formed the Learning Team, and the Learning Partner. At each meeting, the Learning Partner chaired each meeting and reminded each Learning Team of the agenda for the meeting. The Learning Partner asked teachers about their numeracy data collection (on their students), and any issue they had experience or help they required; made suggestions on appropriate numeracy strategies, possible resources and websites, and referred to what some other Learning Teams in the school were doing. The Learning Partner also worked with teachers on their planning, and summarised the meeting at the end. Each group of two teachers used the meetings to clarify what they were doing in their numeracy teaching, explain what they were doing with testing, ask questions of the Learning Partner and their teacher colleague, search for appropriate resources, and work on their numeracy teaching guiding documents.

The following body language and participation was observed throughout the first meeting. The Learning Partner tended to be open, hand and arms on the desk, sitting forward such that she directed more of her conversation to the more vocal (dominant) teacher 1 . Teacher 1 also adopted an open style, used hands for explanation, sitting forward in chair, and was the more dominant teacher. Teacher 2 tended to lean back in chair, hands crossed in lap, and tended towards monosyllabic responses or questions e.g. "yes", "what are you doing with data?”. Despite some unequalness in body language and responses from the first meeting, overall the university observer felt that the atmosphere of the group was one of professionalism, support, positiveness and mutual respect. The only suggestion the university observer had for change after the meeting observation related to the seating arrangement and general interactions between the participants. To encourage more equal participation by both teachers, the university observer suggested that the Learning Partner should sit so that she evenly engaged with both teachers, and be conscious of the need to better engage the less vocal member of each team. These suggestions were taken up successfully by the Learning Partner in the second and third Team meetings.

\subsection{Feedback from Participant Interviews}

The participants were interviewed at the end of this process regarding their perceptions and understandings of the process. The teacher participants demonstrated that they have a good understanding of the purpose of the Professional Learning Teams and the roles each participant had in their team. They explained that the Professional Learning Teams were organised time for professional networking to promote the development of educational 
initiatives internally though our own expertise and knowledge. This was a structured time for teachers to work collaboratively on common goals (in this case numeracy). It provided time for teachers to reflect on themselves and their (numeracy) practices. The introduction of Professional Learning Teams was also seen as opportune in terms of several staff changes that had occurred during the year. Teachers saw the role of their Learning Partner as a collaborator as they worked with other team members to meet the needs of their students. The structure of the sessions was focused on the four key questions, and accessing those in terms of the students within their classes. Each Professional Learning Team worked in its own way to most effectively answer the four key questions: What is it we expect students to learn? What do they already know about what we expect them to learn? How will we know they have learnt it? How will we respond when they don't learn?

Teachers saw their role to be to listen, accept, talk and remain open to change. Representative comments included, "We are creating a culture of collaboration. It's a fundamental happening here", and, "It's a new way that promotes formal and informal sharing”. The focus on the student learning, however, was not sidelined with emphasis on the Team processes, and the teachers frequently talked about numeracy changes they were making, rather than about their role in Professional Learning Teams. Further, they reported changes in their practice, such as in the following response.

“... we are shifting in our understanding of how we teach Maths through professional talk. We are realising that texts have only a small place in the model we are developing. We are focussing more on problem solving activities...”

The participants generally reported that a uniform structure for numeracy blocks needed to be implemented, and that included a combination of explicit teaching, modelling, discussion, group and partner work, independent work and reflection. This, in the teachers' views, required the time of this to be consistent.

\subsection{Feedback from the Staff Survey}

The staff survey allowed the research team to evaluate the process of developing and working through the Professional Learning Teams, by seeking detailed responses from thirteen teaching staff engaged in this process. Most of the questions were each answered by almost all of the respondents.

Nine respondents found Professional Learning Team process to be effective for them, while three indicated that they found the process to be ineffective or very ineffective. Ten reported that for them the Learning Partner was effective or very effective, while one reported the Learning Partner to be neither effective nor ineffective, and for the remaining two that for them the Learning Partner was ineffective.

In terms of identifying challenges of Professional Learning Teams for individuals, most (eleven) related to time, while for the twelfth participant the challenges lay in the "new assessment practices and identifying the specific needs of all students using pre-testing results". Of those reporting time as a challenge, eight suggested there was not sufficient time for Professional Learning Teams, while three were concerned that devoting time to numeracy resulted in less time for other areas.

"Time taken for maths is valuable but ends up taking much more than the hour allocated each fortnight. I find I'm behind in the general daybook planning I usually doing in this time."

"Time! While it's valuable to meet and concentrate on better practice for maths, I end up spending an unbalanced amount of release time on maths and other areas are less organised. I would now prefer to use the [Professional Learning Teams]'s time making and organising the resources needed for maths groups. Talking about it is great but there is a lot of time and organisation needed to facilitate the changes."

Additional themes from the two participants were that the year groups left no time for Stage meetings: "The [Professional Learning Team] group is too small when trying to think of new ideas. It could be more collaborative with larger groups." One participant, in particular, clearly resented the Professional Learning Team process, writing, "[It] occurs during my own release time. Dread going every time... Too much assessing — pre, post etc., [my] students are getting resentful, quality being taken out of learning as I feel like I'm assessing all the time.”

On the other hand, in terms of perceived benefits, the most common theme (seven responses) was that the Professional Learning Teams had resulted in better numeracy outcomes for students. One teacher, for example, reflected, "Love that there is an organised time to meet share ideas and talk about children's learning." The next most popular theme (five responses) related to the benefits of collaboration; a typical comment from this group was: "Collaboration of ideas. People to bounce off and to make sure our grade is on the same page/track." A third theme (four responses) identified professional development and professional discussions: "Wonderful professional development enabling me to improve my teaching practices and hence improving student learning 
and achievement for all children.” Finally, three respondents talked about consistency, one teacher highlighting “... consistency throughout the school, consistent assessment and monitoring of targets and student levels, one leader leading the discussion."

Of course, given the aim of improving student learning in numeracy, it was important to seek the teachers' views on whether they believe that their partnership in a professional leaning team has progressed numeracy in their classroom? All the respondents answered this question. Seven believed that the Professional Learning Teams had progressed numeracy in their classroom, while four reported that it had not; two were undecided. Teachers were then asked to explain their response.

For those responding positively, views reflected teachers' confidence in 1) knowing how individual students were progressing, and 2) their professional role. In terms of better understanding student progress, teaches commented: "I know exactly where each child in my class sits for each mathematics sub-strand due to intensive pre-testing and analysis of results."; "Groups started and progressing well. Doing the Sena 2 [an assessment scheme for early number assessment (DET, 2009)] gave us great insight into where our kids are in number. Analysing the results and grouping the children has been invaluable."; "Great deal more focus on individual achievements and knowing exactly where my students are so I know how to move them forward. Love working together to improve student learning and that its evidence based."; and "I have a good understanding of where the students are with regard to their number strategies. The Sena 2 testing was an excellent opportunity to gain this knowledge. As a result the children are grouped according to strategy used and we are working to move them on to the next strategy. Those commenting on their professional understanding noted: "Better knowledge of the students and professional conversation."; "Fosters collaboration, provides evidence to support effective practices and challenges those that are not based on effective teaching."; and "Helped create pre-assessments for each strand of maths, assisted with collating assessment results, shared ideas to plan maths programme for the next term."

Some teachers, however, were undecided on whether there is any teaching or professional improvement: "It has made me focus on the key learnings rather than some of the periphery indicators, but I am wondering if this will be to the detriment of further learnings." And "Has created a lot of work as yet am not able to compare results." Other teachers, moreover, were not convinced of any significant improvement: "Don't think my targets and levels are different compared to previous years."; "My teaching is still aimed towards improving test results, so it hasn't really changed."; and "Don't feel the results and learning are any better than previous years when we didn’t do [Professional Learning Team]s.”

\section{Results}

For Fullan (2008), sustainable change in education requires a tri-level, whole system, approach where a state or nation, the district and schools work together. Central to this change process, declares Fullan, are teachers, and what they do, and what they think. Schools that are led by principals who encourage strong professional communities are more likely to have a succession of good teachers. Notwithstanding this, both Fullan (2008) and Brown \& Coles (2010) remind us that while educational change is complex, multi-faceted and difficult to accomplish, it is essential. This does not discourage, however, education researchers to examine possibilities for change. Goos' $(2008,2009)$ work, for example, identifies possibilities for shifts in teacher development, recognising first that institutional and learning contexts are important, but, importantly, considering the possibility of extending perceptions of teacher as teacher and teacher as learner. Using Zone theory, theory, she (p. 212) argues that it is possible to bring "teaching, learning and context into the same discussion ....in two connected layers: 1) the teacher-as-teacher... [to] structure student learning; and 2) the teacher-as-learner... negotiating... their own professional learning". Goos continues to discussion "the possibility for investigation of how mathematics teacher educators' knowledge and beliefs define a set of possibilities for their continuing development..., how their professional contexts constrain their actions..., and how they experience and benefit from different opportunities to learn...”. The professional learning teams, and their development and implementation in this case study provide a potential context for this type of examination, and the initial observations recorded here provide insight into some of the practical processes that might underlie Goos' theoretical model.

In 2011, the medium sized regional New South Wales Parish primary school, that is the focus of this case study, embarked on a journey of improvement. Inspired by exemplary practices observed during a districtorganised tour of Melbourne, the school's Principal saw the potential for his school to implement professional 
learning communities. This initiative provided an opportunity to evaluate the development and effectiveness of Professional Learning Teams in improving numeracy in a primary school, an opportunity taken up in this research project. In particular, as the school trialled and evaluated the implementation of Professional Learning Teams, a focus was on the role of the Learning Partner. The project demonstrated that the Professional Learning Teams generally worked well with their Learning Partner; improvements were suggested and implemented as part of the research cycle. Based on the data collected, for example, the Learning Partner focused on effecting greater equality in the team members by encouraging the less vocal members to voice their idea. Further, the Deputy Principal refined the original action plan and introduced a segment on numeracy into the weekly staff meetings.

Summative feedback revealed that the majority of teachers found Professional Learning Teams to be an effective process for them, while a small group of teachers found them to be ineffective. When asked about the effectiveness of the Learning Partner, the results shifted further to the more positive side of the scale most teachers indicating the Learning Partner's effectiveness. For teachers, the benefits of Professional Learning Teams lay in their perception of improvements in numeracy results, the opportunity for collaboration and professional development and professional discussion, as well as the implementation of consistency across the school. The almost common challenge for Professional Learning Teams participants, however, was time.

While this report marks the conclusion of this stage of this particular in-house research project, the school's three-year project is only in its infancy. While it would be good to be able to report tangible evidence of improvements in student performance, that would be premature at this stage; it would be highly unlikely that there would be any significant measure of performance change after the initial implementation stage. More importantly, at this stage, the challenge now for the school is to continue the approach it has begun, by continuing the cycles of observation, review and revision of plans and actions, identifying and building upon new problems, then trialling new actions to determine how improvements can be made. Given this predominantly positive response to the development of a professional learning community to address numeracy teaching and learning effectiveness in this school, and the recognition of the need for further development and learning on the part of the community, it is important to be able evaluate the experience against an external benchmark. One such benchmark is a case study of such numeracy teaching development in a small sample of American middle-level schools, described in some detail by Koellner et al. (2011). That case study identifies key concepts and actions as being critical to professional learning communities supporting maths teacher professional development, key concepts and actions that are, largely, mirrored in this study (Table 2).

The overall ethos of the development of Professional Learning Teams is one in which social values of trust, respect and collegiality play a central role. Koellner et al. (2011: p. 116) describe the importance of "enabling teachers to engage in productive discussions while maintaining a balance between respecting individual community members and critically analysing issues in their teaching”. Such an ethos is articulated through deliberate and informed leadership, both through the school principal or other team leaders, and expected within the team. In the case study reported here, the establishment of agreements on staff behaviour provide a solid basis for trust, respect and collegiality, while the entire process was driven through the leadership and vision of the School Principal.

In practical terms, trust, respect and collegiality are articulated through three key approaches. First, members need to be invited into the process, and need to accept the invitation. i.e. enter the process willingly. This enhances the second key approach, that members take ownership of issues and processes, and that ownership needs to be continuously supported throughout the process. Thirdly, a safe working environment need to be developed and maintained, an environment in which uncertainty and errors are allowed. Such a safe environment allows team leaders to actively help teachers to be comfortable in making mistakes and acknowledging difficulties. In this case study, invitation was a default invitation, following all staff voluntarily agreeing to the agreement on staff behaviour; it could have been more explicit. It is likely that this accounts for some of the misgivings expressed by some staff. Nevertheless, there is evidence for widespread ownership of the issues, and for the successful development of a safe working environment.

In terms of practices, Koellner et al. (2011) identify a wide range of key actions. Importantly the program builds on the teams and their leaders engaging in structured conversation, which allows important issues to be fore-grounded, and allows members to generate their own goals. Goals are intended to meet the members' own needs, and thus the teams must be able to develop shared strategic approaches to achieving these goals. Such goals need to be tailored for the group, and include both long-term goals and workshop goals; the latter is critical in 
Table 2. Benchmarking this study against key concepts and actions for successful development and implementation of a professional learning community (based on case study by Koellner et al., 2011).

Key professional learning community
concepts and actions, adapted from
Koellner et al., 2011
Ethos
- $\quad$ Trust, respect and collegiality
- $\quad$ Leadership from school principal
-
Practical approaches
- $\quad$ Invitation into the process
- $\quad$ Safe working environment
- $\quad$ Time required for lesson planning
- $\quad$ Flarity in individual maths skills
- Focus on impediments for student
understanding
Practices
-
-

Evidence, in this study, of alignment with key professional learning community concepts and actions

Ethos

- Trust, respect and collegiality built through the shared establishment of agreements on staff behaviour

- The program was driven by leadership and vision from the School principal.

Practical approaches

- All relevant staff were involved, although it may be considered that they chose to be involved through accepting the process of establishing the staff behaviour agreements; however, strictly, staff were not involved through invitation, which may explain some of the misgivings amongst some of the staff.

- Ownership of the issues was ensured by all staff being engaged in the school planning processes.

- A safe working environment was established through the staff behaviour agreements, and developed through response to reflective practice.

Practices

- The role of the Learning Partner was important, and recognised by the staff, in providing structure and continuity to discussions.

- The staff worked through what they considered to be important issues, recognising in their feedback the benefits of new perspectives.

- Goal sharing was established through the school strategic planning process, and in the establishment of the professional learning communities.

- The study focused on the early stages of this program, and anticipates continuing work, probably with shifting goals.

- A primary concern amongst some participants was the lack of time for lesson planning, and a sense that other core duties were being neglected at the expense of involvement in this program. It appears that while some staff understood the benefits, to their classroom teaching, of this program, the relationships with this work and lesson planning was probably not made explicit, and was not factored into the program schedule. This would account for much of the misgivings amongst some of the staff.

- It appears that some of the staff recognised, as a consequence of the program, strengths and weaknesses in their maths teaching skills, acknowledging the possibilities of changed practice in their teaching.

- An important focus of discussions was on the students' learning capacities and limitations.

Reflection

- Staff were encouraged and supported to develop reflective practices; this was reinforced through the engagement of the researchers.

- Reflection on process was largely through the action learning engagement of the researcher team, while reflection on learning provide the basis of team discussions.

- Staff encouraged and supported

- Reflection on process and on learning

- Self-reflection

- Modelling and coaching

Self-reflection appears to have been less evident, although in the research feedback it was clear that some staff self-reflected more than others; this may be an element that could be further deliberatively developed.

- The engagement of the Learning Partner, the deputy principal, provided a direct link between the conceptual basis of this program and its implementation, and provided a means to modelling the process; this was, perhaps, less urgent in this study, given that Koellner et al. were also developing the team members as future team leaders, a goal not adopted in this example.

the successful continuing functioning of the team meetings. Such a practical intention requires flexibility in how the team works, with Koellner et al. (2011) describing, for example, how they were open to modifying their workshops based on the needs of participants and prevailing conditions. In terms of developing classroom and teaching skills, several immediate, and crucial, processes are noted: the need for staff to have time for lesson planning; the need for clarity on staff numeracy skills; the acceptance of diversity in teaching ideas and practices; and the central role of identifying impediments to numeracy learning amongst students and focusing on these ("the language of "roadblocks"; p. 130). The case study described here included the active role of structured discussion, overseen by the Learning Partner, which allowed staff to foreground what they saw as important issues, and to set shared goals; the success of such structure collaboration between teachers and the learning partner both reflects the success, reported in another cultural context by Hunter (2010), of such collaboration, and the importance of the constructed and negotiated nature of the relationship: while "change is an important component when teachers and researchers work together to construct classroom communities ...[,] change should be 
premised in the knowledge of both partners” (p. 407).

The program is in its early stages, and it remains to see how flexible or responsive goal setting will be. While there is good evidence for a growing awareness of individual staff numeracy skills, and a significant focus on discussions regarding student needs, a core issue was that of available time. While for some staff, the benefits outweighed time limitation and the possibilities that time spent within the program took away from time on other activities, for some staff this was a serious negative issue, especially in limiting their time for lesson planning. That this does not seem to have been factored into the process is important, and may account for much of the misgivings of some of the staff.

Such an outcome may not be surprising; while Jaworski (2008) has demonstrated that such collaborative activity and sharing of expertise, knowing and experience can contribute positively to the development of a mathematics teaching community, there are issues and tensions that are central to the developmental process. Boylan (2010) reflected on the introduction of any new practice into a school as requiring "to be translated and renegotiated by teachers involved in change initiatives" (p. 394), noting also the need, as part of creating the opportunity for teachers to change themselves, for "the process and means of change [to] be explicitly negotiable”. This reflects the process described here.

A further critical element lies in the central role of reflection. Staff need to be encouraged and supported to reflect on their "own thought processes, ... and make sure they paid attention to their own learning as well as to their facilitation ... [being] encouraged... to self reflecton both their learning... and their facilitation during their workshops" (Koellner et al., 2011: p. 133). Reflection and self-reflection mirrors the core processes of modeling, discussion, and coaching, implicit in the professional learning community approach: "we not only modeled how to promote community, foster [mathematics knowledge for teaching], and adapt [professional development], but also we were explicit about our modeling [, and] our intent was not to be perfect models but rather we drew attention to our attempts and encouraged the [teacher leaders] to similarly be intentional in their behaviours" (Koellner et al., 2011: p. 133). The role of reflection was embedded in the case study reported here as a core approach to developing change in teaching practice. It is also articulated through the involvement of the university partner and research team in shaping reflection on the process of the professional learning community. Although reflection appears to have contributed to the development of mathematics teaching skills, the evidence from staff feedback suggests that self-reflective practice remains to be further developed amongst this professional learning community.

\section{Conclusion}

This case study examines the early stages of the development of a professional learning community in a small regional primary school, aimed at improving teaching, and therefore learning outcomes, in numeracy. While the summative feedback from participants indicates that most of the teachers found the process to be effective, some had misgivings. Benchmarking against a similar implementation reveals that much of the process was sound, which accounts for staff perceptions of improvements in numeracy results, and approval of the opportunity for collaboration, across-school consistency, professional development and professional discussion. However, staff misgivings can be traced to two process weaknesses, namely a default assumption about invitation, recruitment and engagement in the process, and a weakness in managing time to account for existing demands on staff time. Benchmarking also identified an immaturity in self-reflective practice, although such benchmarking difference may reflect the slightly different roles the process played in the benchmark case and this case study. However, the findings highlight the need to address membership recruitment, time management, and the development of self-reflection practices.

\section{References}

ACARA (2012). NAPLAN National Assessment Program Literacy and Numeracy. Sydney: Australian Curriculum Assessment and Reporting Authority. http://www.naplan.edu.au/

ACEL (2011). ACEL: Inspiring Educational Leaders. Australian Council for Educational Leaders. http://www.acelleadership.org.au/

Boyd, W. E., \& Newton, D. (2011). Times of Change, Times of Turbulence: Seeking an Ethical Framework for Curriculum Development during Critical Transition in Higher Education. International Journal of Cyber Ethics in Education, 1, 1-11. http://www.igi-global.com/article/times-change-times-turbulence/56104 http://dx.doi.org/10.4018/ijcee.2011070101 
Boyd, W. E., Healey, R. L., Hardwick, S. W., \& Haigh, M. (with contributions from Klein, P., Doran, B., Trafford, J., \& Bradbeer, J.) (2008). "None of Us Sets out to Hurt People": The Ethical Geographer and Geography Curricula in Higher Education. Journal of Geography in Higher Education, 32, 37-50. http://dx.doi.org/10.1080/03098260701731462

Brown, L., \& Coles, A. (2010). Mathematics Teacher and Mathematics Teacher Educator Change-Insight through Theoretical Perspectives. Journal of Mathematics Teacher Education, 13, 375-382. http://dx.doi.org/10.1007/s10857-010-9159-3

Creswell, J. (2012). Educational Research: Planning, Conducting, and Evaluating Quantitative and Qualitative Research (4th ed.). Boston, MA: Pearson.

DEEWR (2011). Improving Teacher Quality. Canberra: Australian Government Department of Education, Employment and Workplace Relations.

Den Exter, K., Rowe, S., Boyd, W., \& Lloyd, D. (2012). Using Web 2.0 Technologies for Collaborative Learning in Distance Education-Case Studies from an Australian University. Future Internet, 4, 216-237. http://dx.doi.org/10.3390/fi4010216

DET (2009). Count Me in Too: Assessment: The SENA Assesses the Following Aspects of the Learning Framework in Number. Sydney: Department of Education and Training.

http://www.curriculumsupport.education.nsw.gov.au/countmein/assesment.html

DuFour, R., \& Eaker, R. (1998). Professional Learning Communities at Work: Best Practices for Enhancing Student Achievement. Bloomington, IN: National Educational Service.

DuFour, R., Eaker, R., \& Many, T. (2010). Learning by Doing: A Handbook for Professional Learning Communities at Work (2nd ed.). Bloomington, IN: Solution Tree.

Fullan, M. (1982). The Meaning of Educational Change. Toronto, ON: The Ontario Institute for Studies in Education.

Fullan, M. (2007). The New Meaning of Educational Change (4th ed.). New York: Teachers College Press.

Goos, M. (2008). Sociocultural Perspectives on Learning to Teach Mathematics. In B. Jaworski, \& T. Wood (Eds.), International Handbook of Mathematics Teacher Education. Volume 4: The Mathematics Teacher as a Developing Professional (pp. 75-91). Rotterdam: Sense.

Goos, M. (2009). Investigating the Professional Learning and Development of Mathematics Teacher Educators: A Theoretical Discussion and Research Agenda. In R. Hunter, B. Bicknell, \& T. Burgess (Eds.), Crossing Divides: Proceedings of the 32nd Annual Conference of the Mathematics Education Research Group of Australasia (Vol. 1, pp. 209-216). Palmerston North, NZ: MERGA.

HCWG (2008). National Numeracy Review Report. Human Capital Working Group, Council of Australian Governments, Canberra. http://www.coag.gov.au/sites/default/files/national_numeracy_review.pdf

Jaworski, B. (2008). Building and Sustaining Inquiry Communities in Mathematics Teaching Development: Teachers and Didacticians in Collaboration. In K. Krainer, \& T. Wood (Eds.), International Handbook of Mathematics Teacher Education. Volume 3: Participants in Mathematics Teacher Education: Individuals, Teams, Communities and Networks (pp. 309-330). Rotterdam: Sense.

Johnson, B., \& Christensen, L. (2012). Educational Research (4th ed.). Los Angeles, CA: Sage.

Koellner, K., Jacobs, J., \& Borko, H. (2011). Mathematics Professional Development: Critical Features for Developing Leadership Skills and Building Teachers' Capacity. Mathematics Teacher Education and Development, 13, 115-136.

Lloyd, G. M. (2013). The Ongoing Development of Mathematics Teachers’ Knowledge and Practice: Considering Possibilities, Complexities, and Measures of Teacher Learning. Journal of Mathematics Teacher Education, 16, 161-164. http://dx.doi.org/10.1007/s10857-013-9239-2

Schmoker, M. (2005). No Turning Back: The Ironclad Case for Professional Learning Communities. In R. DuFour, \& R. DuFour (Eds.), On Common Ground: The Power of Professional Learning Communities (pp. 135-154). Bloomington, IN: National Educational Service.

Stiggins, R. (2005). Assessment FOR Learning: Building a Culture of Confident Learners. In R. DuFour, \& R. DuFour (Eds.), On Common Ground: The Power of Professional Learning Communities (pp. 65-84). Bloomington, IN: National Educational Service.

Thomson, S., De Bortoli, L., Nicholas, M., Hillman, K., \& Buckley, S. (2011). Challenges for Australian Education: Results from PISA 2009. The PISA 2009 Assessment of Students’ Reading, Mathematical and Scientific Literacy. Programme for International Student Assessment, Australian Council for Education Research, Camberwell. http://www.acer.edu.au/documents/PISA-Report-2009.pdf

Thornton, P., Phelps, R., \& Graham, A. (2011). Teacher Leaders Driving Change: An “In-House Inquiry” Process. The Australian Educational Leader, 33, 8-13.

Yin, R. K. (2009). Case Study Research: Design and Methods. Los Angeles, CA: Sage. 
Scientific Research Publishing (SCIRP) is one of the largest Open Access journal publishers. It is currently publishing more than 200 open access, online, peer-reviewed journals covering a wide range of academic disciplines. SCIRP serves the worldwide academic communities and contributes to the progress and application of science with its publication.

Other selected journals from SCIRP are listed as below. Submit your manuscript to us via either submit@scirp.org or Online Submission Portal.
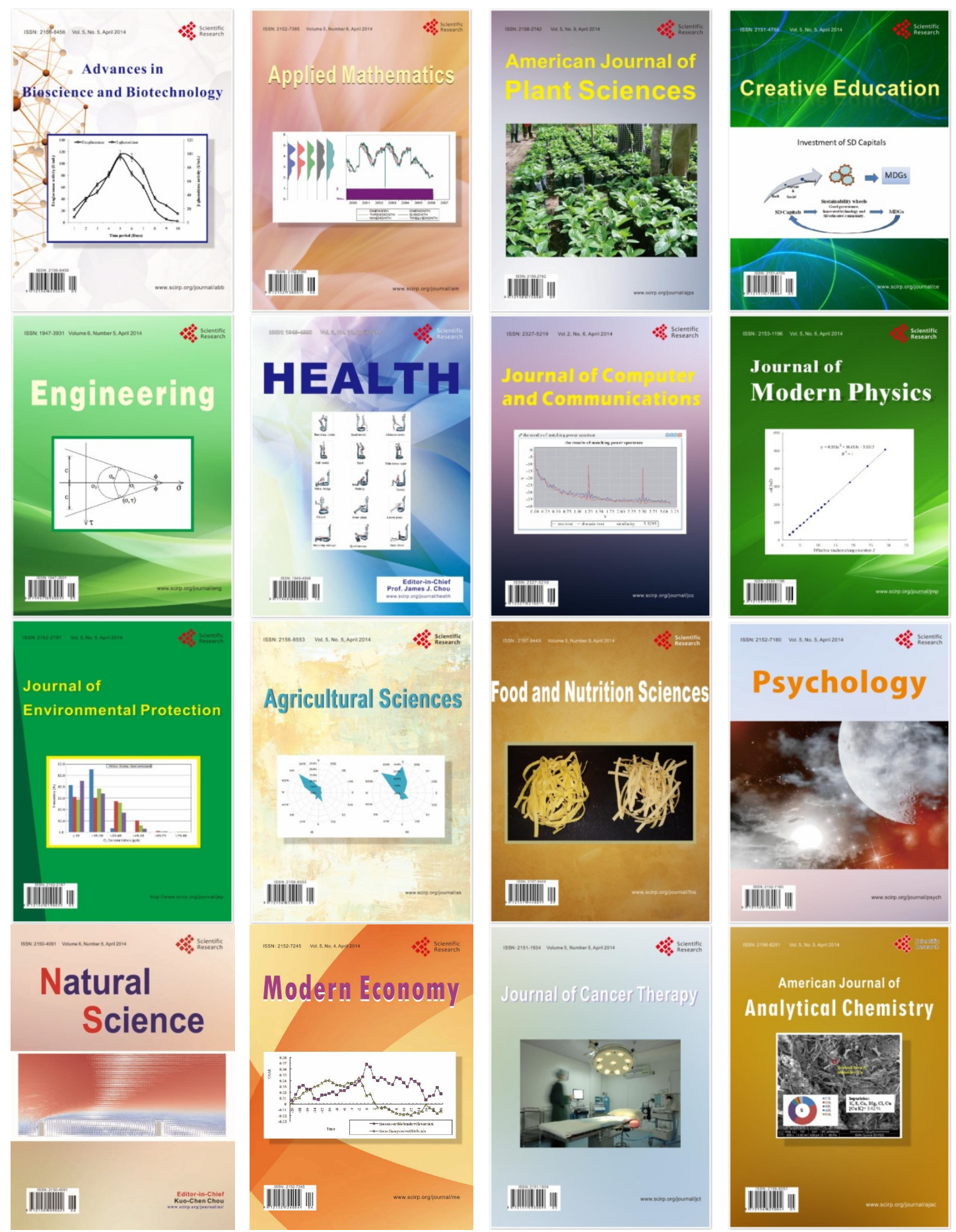